\title{
El nuevo rol de la víctima en el sistema penal acusatorio en México
}

The new role of the victim in the accusatory penal system in Mexico

\section{Roberto Santacruz Fernández $z^{1}$}

${ }^{1}$ Benemérita Universidad Autónoma de Puebla. México. robsantafer@hotmail.com

\section{David Santacruz Morales ${ }^{2}$}

${ }^{2}$ Benemérita Universidad Autónoma de Puebla. México. davesantacruz@hotmail.com https://doi.org/10.22235/rd.v0i17.1572

ReSUmen: Con las reformas constitucionales de 2008 y 2011 en México, la víctima ha adquirido un nuevo rol en el procedimiento penal acusatorio, situación en la que jugaron un papel importante la Victimología, el Garantismo Penal y la maximización de los derechos humanos; por lo que la víctima que había sido excluido hoy es considerada como sujeto procesal con un importante catálogo de derechos derivados de la legislación nacional y los tratados internacionales, por lo que se enfatizado la reparación del daño e implementado la justicia restaurativa, colocando los elementos necesarios para la desvictimación. 
Roberto Santacruz Fernández - David Santacruz Morales, El nuevo rol de la víctima en el sistema penal acusatorio en México, 85- 712 .

Palabras ClaVes: victimología, garantismo penal, sistema penal acusatorio, justicia restaurativa, desvictimación.

ABSTRACT: With the constitutional reforms of 2008 and 2011 in Mexico, the victim has acquired a new role in the adversarial criminal procedure, situation in which played an important role the Victimology, do criminal and the maximization of human rights; by what the victim who had been excluded today is considered as procedural an important catalogue of rights deriving from the national legislation and international treaties, so it is emphasized the reparation of the damage and implemented restorative justice, placing the elements necessary for the no-victimation.

KEY WORDS: victimology, accusatory penal system, restorative justice, do, no-victimation. SUMARIO: Introducción. 1. La nueva dinámica del procedimiento penal acusatorio. 2. La exclusión de la víctima en el sistema penal. 3. De la irrupción de la Victiminología en el Derecho Penal de corte garantista. 4. La posición de la víctima a partir de la reforma procesal penal en México. Conclusiones. Bibliografía. 


\section{INTRODUCCIÓN}

Dentro de las cuestiones polémicas que ha generado la implementación del sistema acusatorio es la constante imputación de tratarse de un modelo que coloca a los delincuentes en una situación de privilegio; sin embargo, bastaría remontarnos al artículo 2 del Código Nacional de Procedimientos Penales para darnos cuenta de que tal situación está alejada de la realidad, puesto que dentro de los objetivos se encuentra el de sancionar al responsable y lograr la reparación del daño.

Con sendos objetivos se pude comenzar a visualizar que el sistema acusatorio también marca nuevos derroteros de la víctima en el procedimiento penal tal como se puede proyectar con la justicia restaurativa, con la inclusión de la denominada acción penal privada y con la protección que le corresponde con la maximización de los derechos humanos, sin olvidar la consideración de sus derechos en el apartado C) del artículo 20 constitucional.

Por lo tanto, es necesario analizar cuál es el papel que tiene la víctima en el procedimiento penal acusatorio y la relación que existe entre éste, el derecho victimal y la victimología, así como la reintegración de la víctima al escenario del drama penal del cual estuvo excluido durante mucho tiempo. Al respecto se ha trabajado sobre la hipótesis de que el establecimiento de un sistema penal de corte garante donde se han maximizado los derechos humanos posibilita el redescubrimiento de la víctima en el procedimiento penal. Para el desarrollo de esta tarea se ha empleado el método analítico puesto que se descompone al objeto en sus partes o elementos para estudiarlo en cada uno de sus elementos, así como sus relaciones entre sí y con el todo. ${ }^{1}$

\footnotetext{
1 Ver al respecto Carlos Manuel Villabella Armengol, La Investigación y la comunicación científica en la ciencia jurídica (México: BUAP-ICI-Universidad de Camagüey, 2009), 124.
} 
Roberto Santacruz Fernández - David Santacruz Morales, El nuevo rol de la víctima en el sistema penal acusatorio en México, 85- 712 .

\section{LA NUEVA DINÁMICA DEL PROCEDIMIENTO PENAL ACUSATORIO}

La reforma constitucional de 2008 marca los principios rectores que rigen el sistema penal en México, así como las cuestiones relativas a la seguridad pública, sin duda dentro de ellos los que más impactado es la incorporación del sistema acusatorio que pretende alcanzar una integración de la justicia penal y combatir viejos vicios como la secrecía, la corrupción y la impunidad. De esta manera la reforma del sistema penal impacta los siguientes aspectos:

a) Nueva dinámica en el procedimiento penal

b) Un sistema penitenciario con la coactuación de los órganos: jurisdiccional y ejecutivo.

c) El sistema de justicia para adolescentes.

d) El establecimiento de la justicia restaurativa

e) Una policía con más funciones en el sistema acusatorio.

El procedimiento penal acusatorio se encuentra matizado por la característica de la oralidad y regido por los principios de contradicción, continuidad, concentración, inmediación, publicidad e igualdad. Sin embargo, uno de los rasgos a loa que se les ha dado mayor énfasis es la oralidad, pero como lo comenta José Nieves Luna Castro: Definitivamente no consiste únicamente en convertir lo escrito en verbal, esa no es la finalidad de la reforma. Esta responde a un diagnóstico realizado por el Centro de Estudios de Justicia de las Américas, organismo dependiente de la Organización de Estados Americanos, de acuerdo con el cual a pesar de carecer de datos estadísticos uniformes, confiables y generalizables, se tuvo a acceso a ciertos datos que reflejaban el estado crítico de la justicia penal por situaciones como las siguientes:

a) Excesiva concentración de facultades del Ministerio Público en la etapa de la averiguación previa

b) Término constitucional reducido, que obligaba al juez a decidir en la instrucción con base al contenido de las pruebas recabadas en la averiguación.

c) El resto de procedimiento penal se encontraba caracterizada por cuestiones como la confusión entre inmediación- cercanía de autenticidad en cuanto a que el juez perciba directamente la prueba- e inmediatez criterio conforme al cual se le asigna mayor valor a aquella prueba más cercana a los hechos-, por lo que este último junto con la prevalencia de la averiguación previa integraban el principio 
de permanencia, por el que perdura el valor obligatorio de las pruebas recabas inicialmente, situación que le daba un cariz inquisitivo al sistema penal mixto mexicano.

d) El resultado de este diagnóstico es que el sistema penal tradicional en México era un sistema injusto e ineficaz. ${ }^{2}$

Sin duda, que además de los mencionados uno de los aspectos críticos del procedimiento penal en México es la cuestión relativa a la víctima de los delitos, en este sentido la Comisión Nacional de los Derechos humanos advertía ${ }^{3}$ :

Sin embargo, a finales del siglo XX y principios del presente, en nuestro país las víctimas del delito continuaban como el eslabón más débil en el sistema de justicia penal, ya que su papel estaba limitado a denunciar. Si querían dar seguimiento a sus casos debían de hacerlo como coadyuvantes y para tener éxito tenían que contratar un asesor jurídico. En caso de no poder pagarlo estaban condenadas a enfrentar la insensibilidad de servidores públicos que no se sentían obligados a asumir la defensa de sus derechos. En general, se les consideraba un participante incómodo en la procuración e impartición de justicia, situación que se pretende revertir con la implementación del nuevo sistema penal acusatorio y oral que prevé la Constitución General de la República, mismo que deberá estar operando en todo el territorio nacional en junio de 2016.

Incluso, el Programa Nacional de Atención a la víctima 2104-2018, señala que "La atención que reciben las víctimas en México no resuelve sus problemas y en ocasiones puede, incluso, empeorarlos, lo que provoca que la política pública en la materia no haya resultado oportuna ni adecuada”. ${ }^{4}$

Como se puede observar uno de los aspectos claves que propiciaron la reforma constitucional del 2008 y, la consecuente, implementación del Sistema Acusatorio es el papel tan débil que tenía la víctima en el anterior modelo del procedimiento penal en donde su carácter de coadyuvante era en realidad una práctica exclusión del drama penal, por lo que la reparación del daño era dirigida en otras jurídicas.

Por otra parte, la reforma constitucional de 2011 vino a robustecer el fundamento de protección a la víctima del delito, puesto que, con base a ella, cualquier autoridad debe ser

\footnotetext{
2 José Nieves Luna Castro, “Introducción y características del Nuevos sistema de justicia penal”, art. cit. en http://www.ijf.cjf.gob.mx/examenaptitud/2015/seleciondepersonal/Luna\%20Castro\%20J\%C3\%B3se\%20Nieves\%20 Fundamentos\%20del\%20nuevo\%20sistema\%20de\%20justicia\%20penal.pdf (fecha de consulta: 25 de junio de 2017). Análisis situacional de las víctimas del delito 2016 http://informe.cndh.org.mx/menu.aspx?id=87 (Fecha de Consulta: 25 de julio de 2017)

4 Programa Nacional de Atención a la Víctima 2014-2018, del Sistema Nacional de Atención a la Víctima https://www.gob.mx/cms/uploads/attachment/file/153590/PAIV-aprobado-por-el-SNAV-20-mayo-20151.pdf (fecha de consulta: 20 de julio 2017)
} 
Roberto Santacruz Fernández - David Santacruz Morales, El nuevo rol de la víctima en el sistema penal acusatorio en México, 85- 172

garante del respeto de los derechos humanos consagrados en el Constitución Política y los Tratados internacionales suscritos por México.

De tal manera que las especulaciones en torno a que el sistema acusatorio es un instrumento cargado a la defensa del delincuente, idéntica situación que se le imputa a las comisiones de derechos humanos, no es correcta, puesto que, si los operadores aplican los lineamientos derivados de la nueva legislación del procedimiento penal, referente a todos los actores, la paridad procesal del sistema acusatorio, también se debe proyectar en beneficio de la víctima del delito.

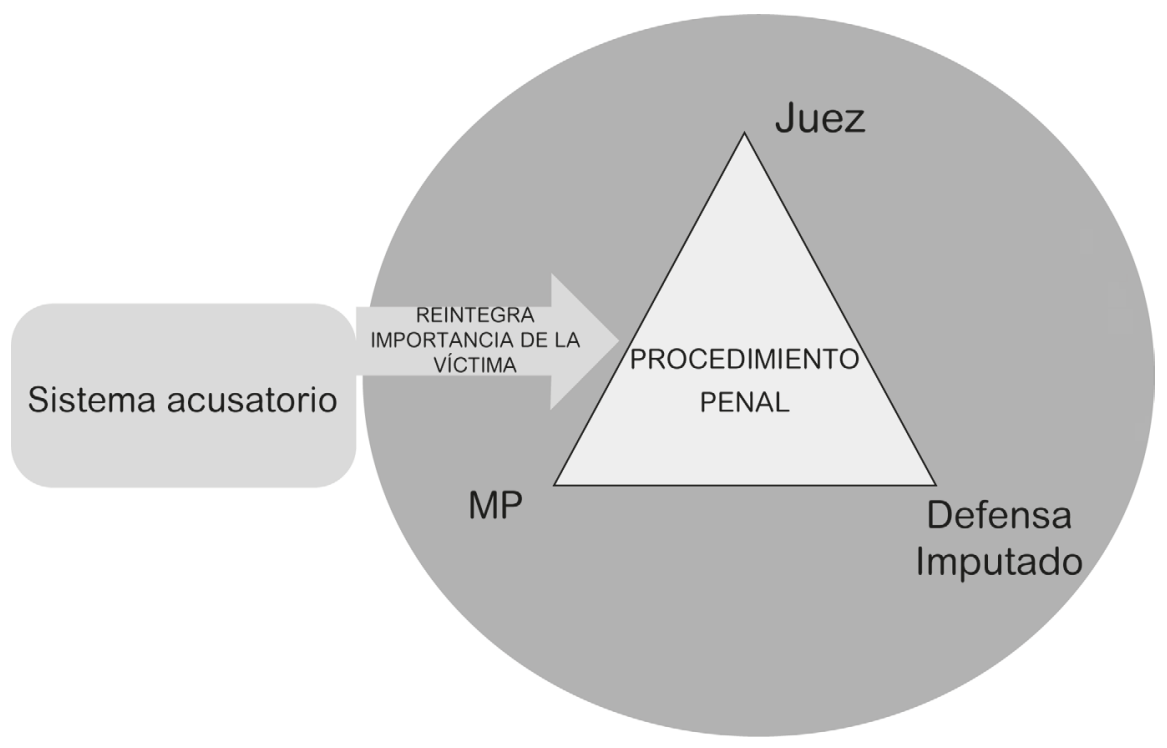

Esquema 1. El Sistema Acusatorio y la Víctima del delito Fuente de elaboración: propia.

Por lo tanto, de acuerdo con este modelo de procedimiento penal acusatorio se ha reintegrado la importancia de la víctima en el procedimiento penal, toda vez que su interés particular había sido relevado por el interés colectivo representado por el Ministerio Público, tal como se proyecta en uno de los objetivos del procedimiento penal relativo a la reparación del daño, la incorporación de la acción penal privada, la justicia restaurativa, la Ley General de Víctimas, así como los denominados procesos de justicia transicional. 


\section{LA EXCLUSIÓN DE LA VÍCTIMA EN EL SISTEMA PENAL}

En el devenir histórico de las cuestiones penales el papel de la víctima ha variado a través del tiempo, si tomamos en consideración las diferentes etapas de evolución de la pena, se puede observar como en la etapa vindicativa la figura más destacada era la de la víctima o el ofendido por la conducta infractora, puesto que éste podía ejercer el derecho de venganza sobre el agresor.

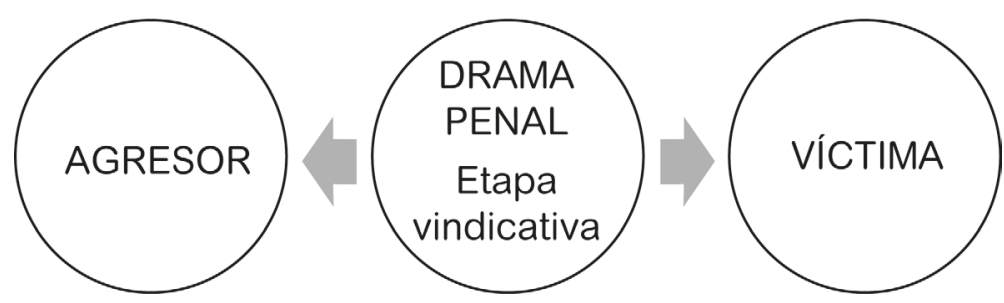

Esquema 2. Elementos del drama penal en la etapa vindicativa Fuente de elaboración: propia

El gran problema de la etapa vindicativa era que en muchas ocasiones la víctima se extralimitaba en el ejercicio del derecho de venganza, provocando un daño mayor al que se le había propiciado, sin tener entonces alguna consecuencia jurídica como sucede hoy, por ejemplo, con quien se excede en la legítima defensa. Desde luego, en esta etapa los elementos integrantes del drama penal estaban bien identificados el agresor y la víctima u ofendido.

Sin embargo, esa situación va a cambiar cuando se constituye la organización política que va a tomar en sus manos la función punitiva, situación que en su desarrollo se ha hecho de elementos como la ley del talión y la compositio, que en su momento histórico marcaron sendos límites a la venganza privada y avanzaron al siguiente período que es el de la venganza pública, que fue avanzando de la crueldad con la aplicación de la pena muerte hasta los aspectos retribucionistas en donde se aplicaba la explotación oficial de los sentenciados para lograr compensar a la sociedad por el daño causado y la expiación de su culpa.

Con el surgimiento del Estado, aunque no se soluciona el hecho de las sanciones inhumanas e injustas, puesto que como señala Zamora Grant $(2014)^{5}$ : "lo que hoy conocemos

5 José Zamora Grant, La víctima en el nuevo sistema acusatorio (México: UNAM-IFP, 2014), 5. 
Roberto Santacruz Fernández - David Santacruz Morales, El nuevo rol de la víctima en el sistema penal acusatorio en México, 85- 712 .

como justicia penal estaba determinada por la inercia de las formas de organización política de la época".

Fue con el iluminismo cuando se sientan las bases para limitar la potestad absoluta del Estado puesto que surge el principio de legalidad, relativo a la definición precisa de los delitos y de las sanciones correspondientes, así como el procedimiento para aplicarlas, es decir, como apunta Gómez Jaramillo (2008)6 " "el derecho de castigar como potestad del soberano, debe supeditarse a la enumeración taxativa que hace la ley penal acerca de los delitos y sus penas, la cual es elaborada por el aparato legislativo en representación del poder popular".

De esta manera mientras el derecho penal va a describir las conductas que se van a considerar delictivas, se requiere un procedimiento mediante el cual se aplique al responsable las sanciones correspondientes, aspecto que durante el desarrollo del positivismo aplicado a las cuestiones sociales va arrojar dos aspectos que van a contribuir a la exclusión de la víctima del drama penal: el modelo de defensa social y la Criminología.

Hacer referencia a la defensa social implica la finalidad de proteger a la sociedad misma, de tal manera, afirma Zamora Grant ${ }^{7}$, que la reacción punitiva se da por la violación al derecho que mantiene los vínculos de los integrantes de la sociedad y no por la afectación de los derechos individuales de la víctima; la víctima, en cuanto tal no interesa.

Con el argumento de la defensa social el Estado toma como suyo el conflicto penal en pro de la defensa del interés colectivo, por lo que releva a la víctima en el drama penal, a quien con el paso del tiempo solo le adjudicaron el papel de coadyuvante en el procedimiento penal. De esta forma, de una relación trilateral entre la víctima, el Estado y el delincuente, queda una relación solo entre el Estado como representante social (como en nuestro país sucedía con el Ministerio Público como titular de la acción penal) y el delincuente como sujeto que concreta los elementos de la conducta descrita en el tipo penal como delito y que reviste interés al violentar la normatividad jurídica que mantiene cohesión del grupo.

Estas ideas se vieron reforzadas con el surgimiento de la denominada Escuela positivista en el Derecho Penal, que en esta área implica la superación de los lineamientos establecidos por la Clásica y que releva la figura central del delito por la del delincuente, propiciando el surgimiento de la Criminología, por Lombroso, Ferri y Garófalo. De esta manera dentro de los postulados de la Criminología Positivista se puede observar lo advertido por Ferri ${ }^{8}$ :

\footnotetext{
Alejandro Gómez Jaramillo, Un mundo sin cárceles es posible (México: Coyoacán, 2008), 66.

Zamora Grant, La víctima... 10.

8 Citado por Antonio García-Pablos de Molina, Tratado de Criminología 5a ed, (España, Tirant lo Blanch, 2013), 400
}

92 Revista de Derecho (UCUDAL). 2da época. Año 14. Nํ 17 (jul. 2018). ISSN 1510-3714. ISSN on line 2393-6193 
La Escuela Criminal Positiva no consiste únicamente en el estudio antropológico del criminal, pues constituye una renovación completa, un cambio radical de método científico en el estudio de la patología social criminal y de lo que hay de más eficaz entre los remedios sociales y jurídicos que nos ofrece.

Por lo tanto, el punto central de la esfera penal se finco sobre el delincuente, que como enfermo social requería de un tratamiento para corregirlo; de esta manera la concreción del delito interesaba porque se tenía que descubrir la etiología de la conducta en un sujeto que no gozaba de libertad, que se encontraba determinado por ciertos factores y que se caracterizaba por la peligrosidad.

Así, el modelo de la defensa social y la criminología positivista contribuyen para que el Estado desplace a la víctima, al asumir la persecución penal en su calidad de representante social que resguarda los valores de la sociedad, de tal forma que los intereses de la víctima quedan al margen de la contienda penal. ${ }^{9}$

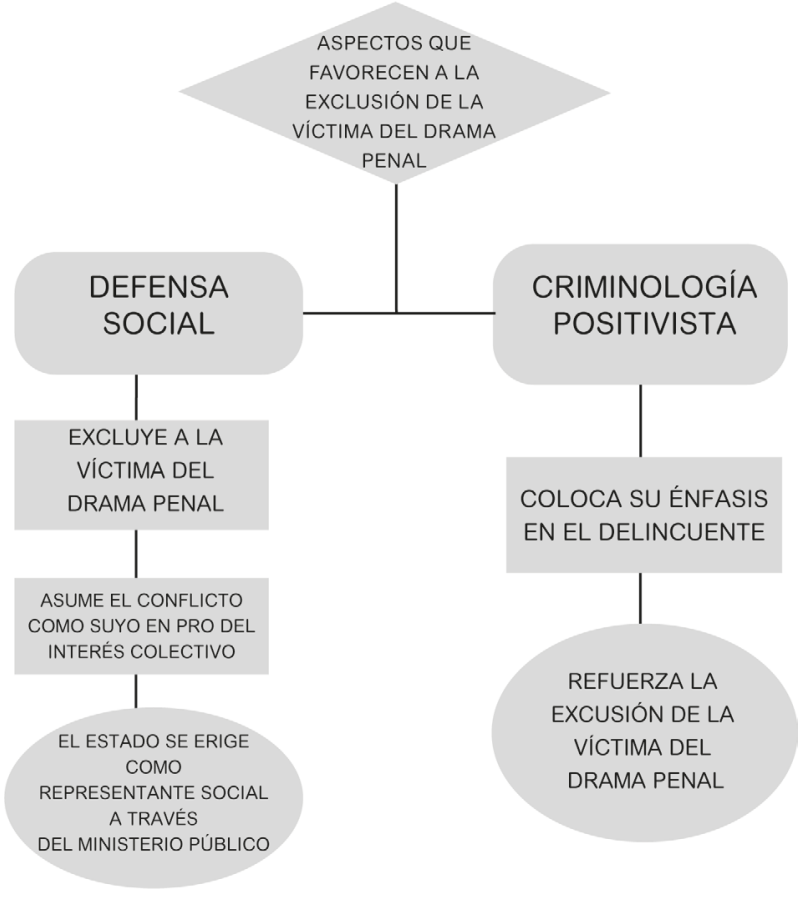

Esquema 3. Aspectos que favorecen la exclusión de la víctima del drama penal

Fuente de elaboración: propia

A. E. Márquez Cárdenas, "La victimología como estudio. redescubrimiento de la víctima para el proceso penal. Prolegómenos. Derechos y Valores”, 2011XIV27-42. Disponible en: http://www.redalyc.org/articulo.oa? id=87619038003. (Fecha de consulta: 15 de junio de 2017). P. 36 
Roberto Santacruz Fernández - David Santacruz Morales, El nuevo rol de la víctima en el sistema penal acusatorio en México, 85- 712 .

De esta manera la víctima fue prácticamente excluida del drama penal, puesto que como señala Zamora Grant:

Que la víctima, en una amplia gama de supuestos situacionales, es la gran olvidada de la práctica penal cotidiana, que no se le presta en la mayoría de supuestos la atención necesaria para salir del trance en que se encuentra, que como persona dañada es la más débil de la relación víctimavictimario, etcétera. Esto ya es — como dice Queralt— communis opinio. ${ }^{10}$

Así, la víctima vivió durante mucho tiempo excluida del procedimiento penal, puesto que se llegó a considerar que otorgar mayor consideración a la víctima implicaría la posibilidad de desvirtuar la naturaleza pública del ordenamiento jurídico penal. Incluso, la neutralización de la víctima se ha justificado porque su consideración nos traslada a un derecho penal, privado, atávico y antigarantista. ${ }^{11}$

Afortunadamente, la irrupción de la victimología, la comprensión de un sistema penal bajo el modelo garante propio de un Estado de Derecho, la maximización de los derechos humanos ha reintegrado a la víctima el papel importante que ocupa en el drama penal.

\section{DE LA IRRUPCIÓN DE LA VICTIMOLOGÍA AL DERECHO PENAL DE CORTE GARANTISTA}

Sin duda, al revisar el ordenamiento jurídico en México, se puede observar que el papel de la víctima ha cambiado, pero llegar a este punto no ha sido una tarea fácil, ha implicado un camino sinuoso en donde la Victimología ha sido trascendental para reintegrar el papel trascendental de la víctima en la esfera penal, desde luego en ese camino también han contribuido las nuevas expectativas de los derechos humanos y la integración de un sistema penal de corte garantista.

10 José Zamora Grant, Derecho Victimal. La víctima en el nuevo sistema penal mexicano, 3a ed. (México: INACIPE, 2016), 143. Al respecto manifestaba Hassemer y Muñoz Conde: la víctima está «neutralizada» y en lugar de la compensación y el acuerdo entre lesionador y lesionado aparece la acción penal pública. Las posibilidades de la víctima de intervenir en el proceso penal son muy reducidas, a pesar de que existen instituciones como la querella, la denuncia, la acusación particular, ofrecimiento de acciones, etc., que directa o indirectamente permiten esa intervención. Francisco Muñoz Conde y Winfried Hassemer, Introducción a la Criminología y Derecho Penal (España: Tirant lo Blanch, 1989), 29

${ }_{11}$ Cfr. Alberto Alonso Rimo, "La víctima en el Sistema de Justicia Penal I", art. cit. en Manual de Victimología Baca Enrique, Enrique Echeborúa y Josep Tamarit, Coords. (España: Tirant lo Blanch, 2006), 309. 
La victimología es una disciplina cuya paternidad es un tanto confusa, puesto que por una parte se atribuye a Mendelshon y, por otra, a Von Hentig, lo cierto es que esta disciplina trajo nuevamente a la palestra a uno de los integrantes del drama penal, desafortunadamente, necesario para su existencia y que es necesario que tenga un papel preponderante en el procedimiento penal, puesto que son sus intereses los que se lesionan o ponen en peligro con la conducta delictiva. Pero ¿qué es la victimología?, ¿Cuál es su objeto de estudio y finalidad? ¿Cómo contribuyo a que la víctima se reintegre como elemento fundamental en la esfera penal? Para dar respuesta a cada una de estas interrogantes es necesario comenzar por conocer el concepto de victimología.

Para Tamarit ${ }^{12}$, la Victimología puede ser definida hoy, en una fórmula de síntesis, como la ciencia multidisciplinar que se ocupa del conocimiento relativo a los procesos de victimación o desvictimación.

En opinión de Hilda Marchiori, la Victimología es una disciplina cuyo objeto lo constituye el estudio científico de las víctimas del delito. ${ }^{13}$

Lima Malvido manifiesta que La Victimología como ciencia autónoma de la Criminología es la ciencia que aporta más respuestas con su metodología, conceptos, técnicas y herramientas a las víctimas en lo individual y a las comunidades para resolver los problemas que se deriven del delito, la violencia y la conflictividad social. ${ }^{14}$

Con estas definiciones se pueden establecer algunos elementos comunes y otros que han generado opiniones contradictorias entre los diferentes estudiosos de la victimología:

a) Se trata de una ciencia autónoma, aunque en este sentido existen autores como Ezzat Fattah, Ellenberg, De Rivacoba, David Abrahamsen, J. A. Sainz Cantero, Günter Kaiser, Yamarellos y Kellens, Amelunxen, y Goldstein, que consideran que se trata de una disciplina dependiente de la Criminología, mientras que otros como Benjamin Mendelsohn, Israel Drapkin y Lola Aniyar de Castro, que la consideran como una ciencia autónoma. Lo cierto es que debemos establecer la autonomía de la Criminología, puesto que una finca su atención en la conducta antisocial y, la otra en la persona que sufre los efectos de esa conducta, desde luego que se encuentran relacionadas a través del principio de interdisciplinariedad.

\footnotetext{
12 Josep Ma Tamarit, "La victimología: cuestiones conceptuales y metodológicas", art. cit. en Manual de Victimologia, 17 .

13 Hilda Marchiori, Criminología. La Víctima del delito, 10ª ed. (México: Porrúa, 2017), 2.

$14 \quad M^{a}$ de la Luz Lima Malvido, "¿Qué aporta el conocimiento victimológico, a la sociedad? ¿y la sociedad al conocimiento victimológico?”, en Revista EGUZKILORE Número 26 (2012) San Sebastián, 87-106. http://www.ehu. eus/documents/1736829/2177136/Lima+Eguzkilore+26-12.pdf, p. 90 (fecha de consulta: 25 de junio de 2017)
} 
Roberto Santacruz Fernández - David Santacruz Morales, El nuevo rol de la víctima en el sistema penal acusatorio en México, 85- 712 .

b) Otro punto interesante es en torno al objeto de estudio, puesto que mientras unos opinan que solo debe referirse a la víctima del delito, otros advierten que ha de atender a cualquier víctima. Al respecto Tamarit manifiesta que debe distinguirse el objeto de estudio en sentido estricto y en sentido amplio, dentro del primero se ocupa de las víctimas de los hechos delictivos, mientras que en el segundo, se interesa también por las víctimas de las catástrofes naturales. ${ }^{15}$ Incluso Mendelshon lo consideraba así al referir a la victimidad a la que consideraba como un concepto general, un fenómeno específico común que caracterizaba todas las categorías de víctimas cualquiera que sea la causa de su situación. ${ }^{16}$ Es evidente que la Victimología debe ocuparse de ambas figuras, que aunque tienen puntos específicos que les distinguen, también guardan elementos comunes que les caracterizan como objeto de la disciplina que comentamos. Desde luego, para los fines de este trabajo nos interesa aquella persona que es afectada por la comisión de un delito.

c) Una de las tareas de la Victimología consiste en explicar los procesos de victimación, que es aquel por el que una persona sufre las consecuencias de un hecho traumático, aquí se incluye todas las situaciones de riesgo que tienen lugar para la precipitación del hecho delictivo y traumatizante, así como el impacto del hecho sobre la víctima. ${ }^{17}$ Se trata, de un aspecto trascendente dentro de la Victimología, puesto que su análisis sirve para proyectar tanto las estrategias para la prevención victimal, como las medidas que han de adoptarse en la atención de las personas que sufren consecuencias del proceso de victimación. Para ello se deben considerar desde el comportamiento de las víctimas hasta las características de los ofensores, sin olvidar las situaciones de riesgo. Precisamente, la asistencia y la prevención victimal se agrupan en lo que se conoce como la desvictimación. ${ }^{18}$

d) Evidentemente, una de las finalidades es incluir la prevención victimal dentro de las políticas públicas para establecer la reducción de situaciones de riesgo y la atención de los grupos vulnerables. De esta manera, Zamora Grant ${ }^{19}$ advierte que

\footnotetext{
15 Tamarit, "La victimología: cuestiones... 18.

16 Citado por Elias Neuman, "Benjamín Mendelshon: precursor de la autonomía científica de la Victimología”, en Iter Criminis, Revista de Ciencias Penales, tercera época, número 7 (2006), INACIPE, 133.

17 Tamarit, "La victimología: cuestiones... 29.

18 Ver al respecto Tamarit, "La victimología: cuestiones... 34, para quien la desvictimación es un proceso de reparación y reconstrucción, entendida así en términos del reconocimiento social, la asistencia y la prevención de revictimación.

19 José Zamora Grant, El Derecho Victimal...212
} 
las políticas en materia de política criminal de fin de siglo retoman como eje de su preocupación a la víctima, por lo que se debe hacer énfasis en su protagonismo.

Con tales premisas, la victimología impulsa el regreso de la víctima a un papel protagónico dentro de la esfera penal, de la cual había sido neutralizada; desde luego con algunos parámetros diferentes, así, cuando hace referencia a la víctima del delito, no lo identifica fehacientemente con el sujeto pasivo de la conducta delictiva.

Al respecto, al abordar el tema del sujeto pasivo, Malo Camacho opina que debe distinguirse entre los conceptos de sujeto pasivo y víctima u ofendido del delito, puesto que aunque frecuentemente se toman como sinónimos, Víctima es la persona física que resulta afectada por la conducta que causa la lesión al bien jurídico, sin que ello sea obstáculo para reconocer como posible sujeto pasivo a un tercero que resultara ser el titular del bien jurídico. ${ }^{20}$ Aquí, se puede citar, en estos términos, el ejemplo del cajero de un Banco, cuando sufre el robo del dinero en la Institución, es la víctima puesto que sufre el desapoderamiento del dinero, mientras que los dueños del Banco son el sujeto pasivo, al ser los titulares del bien jurídico afectado.

Por lo tanto, el concepto de víctima rebasa a la consideración del sujeto pasivo establecido como elemento del tipo penal, incluso el impacto ha sido tal que la Ley General de Víctimas reconoce la existencia de Víctimas directas y Víctimas indirectas, considerando dentro de las primaras a quienes hayan sufrido el daño o menoscabo; mientras que dentro de las segundas se ubica a los familiares o a las personas a cargo de las víctimas directas que tengan relación inmediata con ella. ${ }^{21}$

Ahora, bien, la victimología no ido sola en esta tarea de reivindicar el papel de la víctima en la esfera penal, también es importante mencionar el papel del modelo que rige el sistema penal mexicano como es el garantismo penal y la maximización de los derechos humanos en México.

20 Gustavo Malo Camacho, Derecho Penal Mexicano, 3 a reimp. (México: Porrúa, 2016), 340.

21 El artículo 4 de la Ley General de Víctimas establece: "Se denominarán víctimas directas aquellas personas físicas que hayan sufrido algún daño o menoscabo económico, físico, mental, emocional, o en general cualquiera puesta en peligro o lesión a sus bienes jurídicos o derechos como consecuencia de la comisión de un delito o violaciones a sus derechos humanos reconocidos en la Constitución y en los Tratados Internacionales de los que el Estado Mexicano sea Parte.

Son víctimas indirectas los familiares o aquellas personas físicas a cargo de la víctima directa que tengan una relación inmediata con ella. Son víctimas potenciales las personas físicas cuya integridad física o derechos peligren por prestar asistencia a la víctima ya sea por impedir o detener la violación de derechos o la comisión de un delito. La calidad de víctimas se adquiere con la acreditación del daño o menoscabo de los derechos en los términos establecidos en la presente Ley, con independencia de que se identifique, aprehenda, o condene al responsable del daño o de que la víctima participe en algún procedimiento judicial o administrativo.

Son víctimas los grupos, comunidades u organizaciones sociales que hubieran sido afectadas en sus derechos, intereses o bienes jurídicos colectivos como resultado de la comisión de un delito o la violación de derechos.” 
Roberto Santacruz Fernández - David Santacruz Morales, El nuevo rol de la víctima en el sistema penal acusatorio en México, 85- 712 .

La reforma constitucional de 2008 es llevada a cabo a acorde a los principios penales propios de un Estado de Derecho, lo que ha implicado un sistema penal de corte garantista, el cual tiene su base en los derechos humanos y se identifica con un minimalismo penal.

Para Zamora Grant ${ }^{22}$, "el modelo garantista en la justicia penal se ha traducido en el reforzamiento de los principios garantistas que dieron origen al derecho penal más humanista y respetuoso de los derechos humanos desde hace ya más de dos siglos".

Efectivamente, el garantismo penal supone un minimalismo en el empleo de la violencia, tanto institucional como la derivada del delito, así como la maximización de libertades, lo que incide de manera importante en torno a los límites del ius puniendi.

Y aunque se ha pensado que la referencia al minimalismo penal es el énfasis en la cuestión del derecho penal y los elementos que le conforman en las tres dimensiones del ius puniendi (legislativo, judicial y ejecutivo), ello no significa la exclusión de la víctima, por el contrario al limitar este derecho de intervención punitivo del Estado implica dar certeza a las libertades fundamentales de quienes participan en el hecho surgido a partir de la comisión de un delito: el sujeto activo del delito y la víctima. Tal situación se puede desprender de los siguientes puntos expuestos por el creador del Garantismo Penal:

a) “...'garantismo'... designa un modelo de derecho orientado a garantizar derechos subjetivos". ${ }^{23}$ Con ello, observamos que una de las características primordiales del Garantismo Penal es la de otorgar certeza a los derechos humanos, sin establecer un límite por la calidad específica del titular, sino que se dirige a todos los integrantes de la población, le que le constituye como un modelo incluyente de la víctima y del sujeto activo del delito.

b) "Las garantías por cuanto incorporadas en las constituciones, se configuran ni sólo como fuentes de justificación externa o política de la existencia del derecho penal, sino también como fuentes de legitimación jurídica y política de las concretas decisiones penales". ${ }^{24}$ Las garantías constitucionales que tienen por objeto la protección de los derechos humanos, no cargan la balanza hacia un grupo en particular, puesto que tienen carácter universal, por lo tanto, se erigen con el fundamento que legitima la existencia del derecho penal, que a través de la creación del tipo penal tiene el objetivo de proteger los bienes jurídicos fundamentales, lo que se proyecta como el primer punto de protección de una víctima potencial. Tal situación trae como consecuencia que cuando se concretan los elementos del

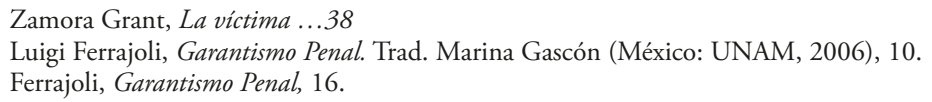


particular tipo legal, el sistema penal se pone en movimiento para proteger a la víctima por la lesión o puesta en peligro de su interés particular o colectivo, de orden social.

c) "El fin general del derecho penal, tal como resulta de la doble finalidad preventiva recién ilustrada, consiste entonces en impedir la razón construida, o sea en la minimización de la violencia en la sociedad...Dicho fin supone más bien la protección del débil contra el más fuerte, tanto del débil ofendido o amenazado por el delito, como del débil ofendido o amenazado por las venganzas; contra el más fuerte, que en el delito es el delincuente y en la venganza es la parte ofendida o los sujetos con ella solidarios" ${ }^{25}$ Nada más explícito que esta explicación de parte de Luigi Ferrajoli, la protección del más débil, donde no solo considera al delincuente, sino al ofendido, esta parte es totalmente ilustrativa de cómo el garantismo penal es incluyente de la víctima, tal situación se manifiesta en todo el conglomerado de normas jurídico-penal que se erigen bajo este modelo en un Estado de Derecho, como se explicará en el apartado número 4 de este trabajo.

d) Luigi Ferrajoli advierte de los riesgos del derecho penal máximo y sus mensajes como sucede en el caso de la seguridad, uno de ellos es el siguiente: "seguridad pública”, reducida a la forma del orden público de policía, en lugar de la que se refiere al estado social. ${ }^{26}$ Sin duda, este es un punto sobre el que debe ponerse atención, puesto que en lugar del populismo punitivo, generando tipos penales y dirigiéndose a la seguridad punitiva, se tendría que poner énfasis en el desarrollo de políticas sociales que incidan sobre las condiciones de vida y contribuyan a las estrategias de prevención del delito y a la desvictimación.

Desde luego, no se pretende hacer un análisis de todo el garantismo penal, pero con los aspectos comentados se puede observar que de ninguna manera el garantismo penal excluye a la víctima de la esfera penal, por el contrario de no tomarla en consideración la expectativa que persigue quedaría incompleta y significaría mantener o incrementar la violencia contra la víctima y su neutralización, como ha sucedido en épocas anteriores.

Otro de los rubros que ha impulsado la reincorporación de la importancia de la víctima en el drama penal son las nuevas consideraciones de los derechos humanos en México, puesto que a partir de las reformas constitucionales del ańo 2011 se ha generado la maximi-

25 Luigi Ferrajoli, Derecho Penal Minimo, http://www.nparangaricutiro.gob.mx/Libros/31.-\%20El\%20 Derecho\%20Penal\%20M\%C3\%ADnimo\%20-\%20Ferrajoli,\%20Luigi.pdf (Fecha de consulta, 25 de junio de 2017): 15 y 16.

26 Ferrajoli, Garantismo Penal, 59. 
Roberto Santacruz Fernández - David Santacruz Morales, El nuevo rol de la víctima en el sistema penal acusatorio en México, 85- 712 .

zación de aquellos, incluso de su protección con figuras como el control de convencionalidad y el principio pro persona.

Con el control de convencionalidad se pretende el respeto de los derechos humanos considerado en el corpus iuris internacional, es decir considerar no solamente aquellos derechos fundamentales consagrados en la Constitución Política Federal sino también aquellos considerados en los tratados internacionales suscrito por México. Así en torno a las víctimas se pueden encontrar entre otros los siguientes instrumentos internacionales:

a) Reglas Mínimas de las Naciones Unidas Para La Administración De La Justicia Penal (“Reglas de Mallorca”): dentro de las cuales se hace alusión a la víctima en sus artículos del $40 \mathrm{al}$ 43, donde se requiere un trato humano digno, dispensarles la ayuda que necesiten, cuestiones relativas a la reparación del daño y la defensa de la víctima.

b) La Convención Americana sobre los Derechos Humanos (Pacto de San José de Costa Rica): en cual se establece la obligación de respetar los derechos humanos a todos los Estados que formen parte de la Convención, sin discriminación alguna; además deberán proteger la honra y dignidad de las personas.

c) Declaración Sobre Los Principios Fundamentales De Justicia Para Las Víctimas De Delitos Y Del Abuso De Poder (Resolución 40-34 De La Asamblea General De Las Naciones Unidas De 1985): uno de los documentos más importantes en torno a la víctima, estableciendo su definición, su derecho de acceso a la justicia y trato justo, cuestiones relativas al resarcimiento e indemnización, la asistencia de la víctima y los aspectos relativos a las víctimas del abuso de poder.

d) Declaración Universal de los Derechos Humanos: que desde luego establece que todo individuo tiene derecho a la vida, a la libertad y a la seguridad de la persona, establece la igualdad ante la ley y el derecho de acceso a la justicia ante la vulneración de sus derechos fundamentales.

e) El Estatuto de Roma de la Corte Penal Internacional, establece en su artículo 68 la protección de las víctimas y los testigos y su participación en las actuaciones, con el objeto de proteger a las víctimas y establecer las pautas para su intervención en las diferentes actuaciones del procedimiento penal.

Como se observa existen diversos instrumentos internacionales que se pronuncian por la protección y salvaguarda de los derechos de las víctimas y, que desde luego al estar suscrito por México son de aplicación en el territorio nacional. 
Relacionado con ello, se encuentra el principio pro persona que es un mandato constitucional a través del cual se busca favorecer en todo momento la protección más amplia de la persona, el cual tiene relevancia en el proceso de interpretación de las normas que determinan el contenido y alcance de los derechos, sea cual fuere su fuente o rango dentro de un sistema jurídico determinado. ${ }^{27}$ Obviamente, el principio pro persona tiene lugar en cuanto a los derechos de la víctima dentro del procedimiento penal, en su atención y prevención victimal.

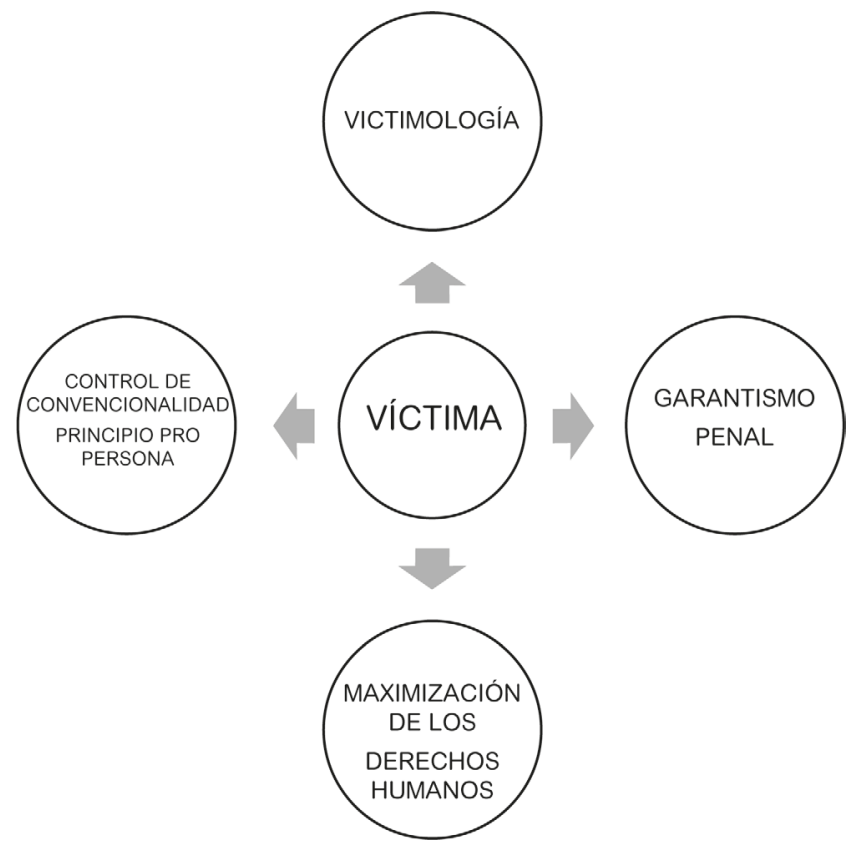

Esquema 4. Elementos que contribuyen a reintegrar el papel importante de la víctima en el drama penal

Fuente de elaboración: propia

Como se ha podido establecer la Victimología, el Garantismo Penal, la maximización de los derechos humanos-que han traído el control de convencionalidad y el principio pro persona- han contribuido a reintegrar a la víctima el papel preponderante que debe tener en el drama penal, después de que durante mucho tiempo se le neutralizó de dicho contexto.

27 Ver al respecto Ximena Medellín Urquilaga, Principio pro persona (México: CDHDF, 2013), 68. 
Roberto Santacruz Fernández - David Santacruz Morales, El nuevo rol de la víctima en el sistema penal acusatorio en México, 85- 712 .

\section{LA POSICIÓN DE LA VÍCTIMA A PARTIR DE LA REFORMA PROCESAL PENAL EN MÉXICO}

Una de las principales consecuencias de la reforma constitucional de junio de 2008 en México es la implementación del Sistema penal acusatorio, el cual responde al corte garantista del Estado de Derechos que se erige sobre el respeto de los Derechos Humanos. Sin embargo, la praxis del procedimiento penal acusatorio no ha sido nada fácil y ha estado envuelto en una serie opiniones encontradas que han llegado a establecer el anhelo del regreso al viejo paradigma del sistema penal mixto que regía anteriormente.

Sin embargo, las críticas y anhelos en ese tenor resultan carentes de fundamento y llenos de olvido, puesto que además de la secrecía, la escritura, la corrupción y la impunidad existentes, se presentaba una neutralización de la víctima, lo que significaba prácticamente su exclusión del procedimiento penal, otorgándolo un papel de coadyuvante, que tampoco servía de mucho y sí se reflejaba en una violación de sus derechos y la ausencia de la reparación del daño.

Ahora bien, las nuevas consideraciones en torno a la víctima no son nuevas en México, puesto que el impulso dado por la Victimología se visualizó en el año 2000 con la reforma publicada el 21 de septiembre en el Diario Oficial de la Federación en la que se organiza el contenido del artículo 20 constitucional en dos apartados el A) relativo a los derechos del inculpado y, el B) referente a los derechos de la víctima.

Con ello, se llega a hablar del derecho victimal, el cual se puede definir como un conjunto de normas jurídicas que regulan los mecanismos de difusión, concreción y protección de los derechos de las víctimas, la atención de aquellas y los medios para lograr la reparación integral del daño. ${ }^{28}$ De esta manera, los derechos de la víctima se alejan de una simple declaración de buena voluntad y se colocan en la línea de protección del ordenamiento jurídico.

Pero cuál es el papel de la víctima en el sistema penal acusatorio, para visualizarlo, se debe partir de los ordenamientos jurídicos nacionales al respecto:

a) Fundamento constitucional: se encuentra en el apartado C) del artículo 20 constitucional, el cual establece los derechos de la víctima u ofendido, dentro de los que se encuentran: recibir asesoría jurídica, coadyuvar al Ministerio Público, recibir atención médica y psicológica de urgencia, la reparación del daño, resguardo

28 Ricardo Hernández Martínez, Elementos de Criminología (México: S/E, 2017), 45. 
de la identidad (en el caso de los menores de edad o cuando se trate de delitos de violación, trata de personas, secuestro o delincuencia organizada), la aplicación de medidas cautelares y providencias para la protección y restitución de sus derechos; impugnar ante autoridad judicial las omisiones del Ministerio público, así como las resoluciones de reserva, no ejercicio, desistimiento de la acción penal o suspensión del procedimiento cuando no esté satisfecha la reparación del daño. Por otra parte, se encuentra el artículo 21 constitucional que en su segundo párrafo establece la posibilidad de la acción penal particular ante las autoridades judiciales.

b) Código Nacional de Procedimientos Penales, comenzando por el artículo 2 que determina dentro de los objetivos del procedimiento penal-retomado lo establecido en la fracción I del apartado A) del artículo 20 constitucional-: la reparación del daño. También establece el capítulo II (artículo del 108 al 111) relativo a la víctima u ofendido; en este hace una diferencia entre la víctima, que es el sujeto pasivo del delito-que es la persona que sufre directamente las consecuencias de la conducta delictiva-, y el ofendido, que es la persona física o moral titular del bien jurídico afectado. Por otra parte establece un catálogo de derechos de la víctima dentro de los cuales se observa el derecho de acceso a la justicia pronta, gratuita e imparcial y la prestación de servicios que constitucionalmente tienen encomendados con legalidad, honradez, lealtad, imparcialidad, profesionalismo, eficiencia y eficacia y con la debida diligencia, el trato con respeto y dignidad, el derecho a un asesor jurídico, prohibición de un trato discriminatorio, asistencia de un intérprete, a que se le reciban todos los datos yo elementos de prueba con los que cuente, a intervenir en todo el procedimiento penal, a que le sean restituidos sus derechos, cuando estén acreditados, a que se le garantice la reparación del daño, entre otros.

c) Ley nacional de mecanismos alternativos de solución de controversias en materia penal: en la que la participación de la víctima es esencial y que tiene por objetivo establecer los principios, bases, requisitos y condiciones de los mecanismos alternativos de solución de controversias en materia penal que conduzcan a las Soluciones Alternas previstas en la legislación procedimental penal aplicable. Es para la víctima el acceso a la justicia restaurativa. 
Roberto Santacruz Fernández - David Santacruz Morales, El nuevo rol de la víctima en el sistema penal acusatorio en México, 85- 712

Ley General de Víctimas: la cual tiene como objetivo la protección de los derechos de las víctimas del delito y de violaciones de derechos humanos. Clasifica los derechos de las víctimas en: generales; de ayuda, asistencia y atención; de acceso a la justicia, derechos en el proceso penal y, el derecho a la verdad. Establece medidas de reparación integral y establece el Sistema Nacional de atención a las víctimas.

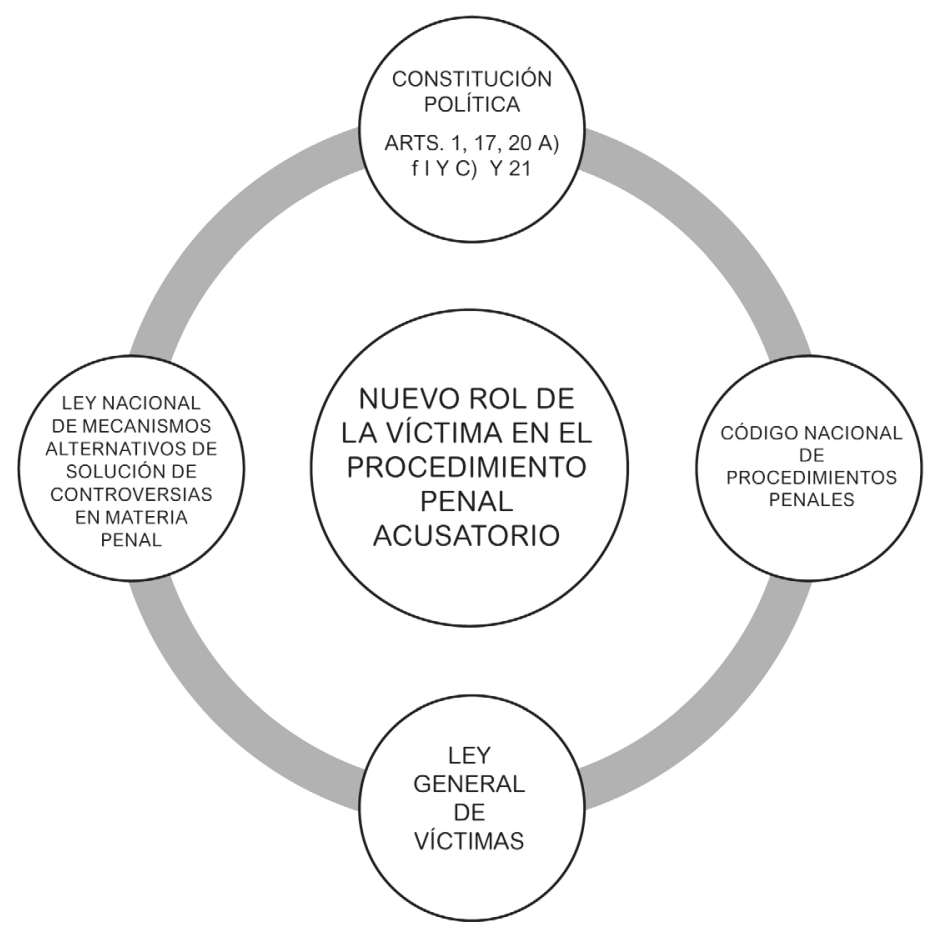

Esquema 5. Redescubrimiento de la víctima en el sistema penal acusatorio Fuente de elaboración: propia 
Una vez que se ha hecho alusión al marco jurídico fundamental de los derechos de la víctima, es necesario establecer cuál es el papel de aquella en el procedimiento penal acusatorio.

En este sentido Zamora Grant manifiesta: "Al considerarse parte a la víctima en los procesos acusatorios, la igualdad procesal exige de estos un depurado equilibrio entre las fuerzas intervinientes, ya que habrá de limitarse los poderes de los fuertes y reforzarse los poderes de los débiles, para que en igualdad de oportunidades pueda hacer valer sus respectivos derechos y alcanzar en justicia sus pretensiones" ${ }^{29}$

Precisamente esta igualdad entre las partes se encuentra regulada en el Código Nacional de Procedimientos Penales, en el artículo 11 se dispone: "Se garantiza a las partes, en condiciones de igualdad, el pleno e irrestricto ejercicio de los derechos previstos en la Constitución, los Tratados y las leyes que de ellos emanen".

De tal manera que también la víctima goza del pleno e irrestricto ejercicio de sus derechos consagrados en la Constitución y los Tratados internacionales, desde luego con ello se confirma el parámetro de protección de los derechos humanos establecido en el artículo 1 constitucional, específicamente en los tres primeros párrafos. Desde luego, con tales supuestos contenidos en la normatividad jurídica se termina con la neutralización de la víctima, que le quitaba todo papel trascendente durante el procedimiento penal.

Por lo tanto, en términos de lo establecido en el artículo 17 constitucional, en el segundo párrafo y el artículo 2 del Código Nacional de Procedimientos Penales, establecen dentro de los derechos de las partes el de acceso a la justicia. En este sentido, ya conocemos uno de los medios de para dar inicio al procedimiento penal por parte de la víctima: denuncia, querella o por su equivalente cuando la ley lo exija. La denuncia puede ser presentada por cualquier persona que tenga conocimiento del delito, siempre que se trate de aquellos que se persiguen de oficio; la querella tiene lugar cuando se exige la petición de parte ofendida u víctima, para dar inicio a la investigación del delito. Hasta aquí, son puntos que ya existían para poner en conocimiento de la autoridad la comisión de un delito. ${ }^{30}$

Una de las innovaciones del procedimiento penal acusatorio es que la víctima u ofendido tienen el derecho de promover una acción penal por particulares y para ello se deben cumplir los supuestos siguientes: ${ }^{31}$

\footnotetext{
Zamora Grant, La víctima... 83.

Ver al respecto artículos del 221 al 226 del Código Nacional de Procedimientos penales.

Ver artículos del 426 al 432 del Código Nacional de Procedimientos Penales.
} 
Roberto Santacruz Fernández - David Santacruz Morales, El nuevo rol de la víctima en el sistema penal acusatorio en México, 85- 712

Debe tratarse de un delito perseguible por querella, con penalidad alternativa, distinta de la privativa de libertad o cuya punibilidad no exceda de tres años de prisión.

Acudir ante el Juez de control para ejercer acción penal cuando cuente con datos-aportar datos de prueba que sustenten la acción- que permitan establecer que se ha cometido un hecho que la ley describe como delito y exista la posibilidad de que el imputado lo concreto o participó en su comisión.

Cuando debido a la investigación del delito sea necesario realizar actos de molestia que requieran control judicial.

Con tales aspectos establecidos en la legislación procesal se regula lo establecido en el artículo 21 constitucional que establece que la ley determina los casos en los que procede la acción penal por particulares ante la autoridad judicial. Al presentar la acción penal privada el particular puede solicitar la orden de comparecencia del imputado o su citación a la audiencia inicial, así como el reclamo de la reparación del daño. Una vez que asume la responsabilidad de ejercer la acción penal privada, el particular no podrá acudir al Ministerio Público. Una vez que se inicia la referida acción se aplican todas las disposiciones inherentes al procedimiento penal acusatorio.

Otras de las figuras inherentes a la víctima es la denominada Justicia Restaurativa. Al respecto Fattah $(2014)^{32}$ señala: "Parece evidente que el futuro de la Victimología influirá, y será influenciado por, la evolución del sistema de justicia. Debido a esto, el futuro de la victimología dependerá en gran medida del grado en que se acepte y se implemente el paradigma de la "justicia restaurativa”.

En México, con la llegada del sistema penal acusatorio se ha implementado la denominada justicia restaurativa que ha sido definida de la siguiente forma:

Es una forma de responder al comportamiento delictivo balanceando las necesidades dela comunidad, de las víctimas y de los delincuentes...Un "proceso restaurativo" se define como "todo proceso en que la víctima, el delincuente y, cuando proceda, cualesquiera otras personas o miembros de la comunidad afectados por un delito participen conjuntamente de forma activa en la resolución de las cuestiones derivadas del delito, por lo general con la ayuda de un facilitador" ${ }^{33}$

32 Ezzat A. Fattah, "Victimología: pasado, presente y futuro, Revista electrónica de Ciencia Penal y Criminología. Reflexiones RECPC 16-r2 (2014)”, http://criminet.ugr.es/recpc/16/recpc16-r2.pdf (Fecha de consulta: 23 de junio de 2017), 23.

33 Yvon Dandurand, Manual sobre Programas de Justicia Restaurativa (Estados Unidos: Naciones Unidas, 2016), 4. 
En el tenor de la justicia restaurativa se ha creado en México la Ley Nacional de Mecanismos Alternativos de Solución de Controversias en Materia Penal y que tiene por finalidad en términos del segundo párrafo del artículo 1: propiciar, a través del diálogo, la solución de las controversias que surjan entre miembros de la sociedad con motivo de la denuncia o querella referidos a un hecho delictivo, mediante procedimientos basados en la oralidad, la economía procesal y la confidencialidad.

Los mecanismos alternativos se pueden aplicar desde el inicio del procedimiento hasta antes de que se dicte el auto de apertura a juicio o antes de que se formulen conclusiones. La conciliación y la mediación son mecanismos alternativos, mediante los cuales se proponen opciones de solución a la controversia planteada. Aunque se ha cuestionado la justicia restaurativa por el margen de impunidad que supone, lo cierto es que puede facilitar la restauración del daño en su más amplia concepción, situación que es prioritaria para la víctima del delito.

Además, la solución mutuamente aceptada tiene un seguimiento para el cumplimiento del acuerdo correspondiente y con cumplimiento exigible, en caso de no cumplirse, la victima puede optar por la continuación del procedimiento penal. ${ }^{34}$ Desde luego, aunque con los mecanismos alternativos se atienden las necesidades de los involucrados en el conflicto penal, es indiscutible que con ellos, las víctimas forman parte activa en el proceso de solución, puesto que la pretensión primordial es cubrir sus necesidades.

Desde luego, la justicia restaurativa resulta un paradigma que intenta transformar a la justicia retributiva en un modelo basado en la atención de la víctima. Al respecto Sampedro manifiesta:

La justicia restaurativa tiene como punto de partida el reconocimiento de que las víctimas son una realidad presente que nos habla de las injusticias del pasado y nos obliga a tomar en cuenta sus derechos como el camino obligado a seguir para la construcción de una sociedad más humana; es una propuesta que propende por el diseño de una justicia de las víctimas sin venganza que fije su mirada en el sufrimiento de los inocentes, en la reparación del daño ocasionado voluntariamente y la proyecte como un valor superior, condición ineludible de la paz ${ }^{35}$

34 Ver al respecto artículos del 33 al 39 de la Ley Nacional de Mecanismos Alternativos de Solución de Controversias en Materia Penal.

35 Julio Andrés Sampedro-Arrubla, "La justicia restaurativa: una nueva vía, desde las víctimas, en la solución al conflicto penal17", International Law, Revista Colombiana de Derecho Internacional, 87-124 (2010). http://www.scielo. org.co/pdf/ilrdi/n17/n17a04.pdf (Fecha de consulta: 25 de junio de 2017). 
Roberto Santacruz Fernández - David Santacruz Morales, El nuevo rol de la víctima en el sistema penal acusatorio en México, 85- 712 .

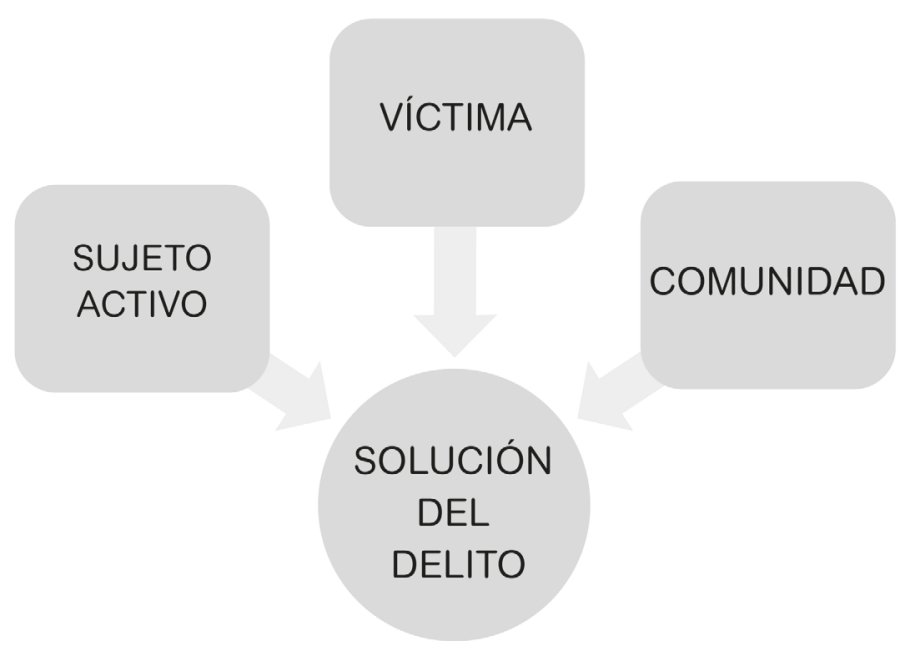

Esquema 6. La justicia restaurativa medio para la solución del delito Fuente de elaboración: propia

Incluso la Ley General de Víctimas establece que la solución de conflictos persigue la reparación del daño y la reconciliación de las partes, así como el de evitar la reincidencia.. ${ }^{36}$ Por lo tanto, estos medios alternativos de la justicia penal en el modelo acusatorio, tiene por objeto el efecto restaurador en la víctima, pero también contribuir en la reintegración del sujeto activo del delito a la comunidad de manera tal que evita la reincidencia, desde luego para ello es necesario la capacitación de las instituciones que intervienen en la mediación y en la conciliación, así como generar las políticas públicas que propicien las estrategias de resocialización, no haciendo énfasis de manera exclusiva y como prima ratio en la sanción penal sino con el apoyo de políticas sociales.

Ahora bien, la justicia restaurativa, no se traduce en un mero acuerdo conciliatorio, sino que la víctima debe obtener la reparación integral del daño, lo que significa restitución en sus derechos conculcados, así como en sus bienes y propiedades si hubieren sido despojadas de ellos. ${ }^{37}$

Sin duda, este nuevo rol de la víctima en el procedimiento penal acusatorio implica toda una transformación que le ha trasladado de un papel de simple coadyuvante a colocarlo como sujeto procesal del procedimiento con una serie de derechos consagrados en la legis-

\footnotetext{
Ver al respecto art. 17 de la Ley General de Víctimas.

Ver al respecto artículo 61 de la Ley General de Víctimas.
} 
lación nacional como en los instrumentos internacionales que sean suscritos por México. Es importante advertir que, para la protección, ayuda, asistencia, atención, acceso a la justicia, a la verdad y a la reparación integral, la víctima cuenta con el Sistema Nacional de Atención a víctimas, que es la instancia superior que establece las políticas públicas al respecto. Este sistema se integra por órganos de los Poderes Ejecutivo, Legislativo y Judicial, así como por la Comisión Nacional de los Derechos Humanos y la Comisión Ejecutiva de Atención a Víctimas y un representante de las comisiones ejecutivas locales, quien preside este Sistema es el presidente de la República Mexicana. ${ }^{38}$

Este redescubrimiento de la víctima en el sistema penal acusatorio es coherente con un Estado de Derecho, en donde el fundamento es de corte garantista, tal situación que se ha caracterizado por pregonar el minimalismo del derecho penal, que implica una reducción en la violencia de toda índole-la delictiva y la generada por la reacción social-se proyecta en la maximización de los derechos humanos, no solamente de los personas que participan como sujetos activos del delito, sino también de aquellos que son afectados por la conducta delictiva: las víctimas, tanto directas como indirectas.

De tal manera, que pensar que la implementación del sistema penal acusatorio es un instrumento pensado en el imputado, en el sujeto activo del delito, es una proyección limitada de un modelo de procedimiento penal basado en el respeto de los derechos humanos de todos los participantes y donde la víctima juega un papel primordial, no solo para la solución del conflicto sino para las estrategias de la prevención de la antisocialidad, del delito y de los procesos de victimación.

\section{CONCLUSIONES}

La víctima que jugó un papel preponderante durante la etapa vindicativa mediante el ejercicio del derecho de venganza, por lo que prácticamente le correspondía la función punitiva; cuando la organización estatal obtiene dicha función, el papel de la víctima empezó a mermar hasta llegar el punto de excluirle del drama penal, tal situación se visualizaba en su esplendor en el momento en que el ministerio público era el representante social, por la afectación al interés colectivo, sin dar mayor relevancia al afectado por la conducta delictiva.

En la exclusión de la víctima del procedimiento penal incidieron el modelo de defensa social y la criminología positivista de Lombroso, Ferri y Garófalo; puesto que3 mediante la

38 Ver al respecto artículos del 79 al 83 de la Ley General de Víctimas. 
Roberto Santacruz Fernández - David Santacruz Morales, El nuevo rol de la víctima en el sistema penal acusatorio en México, 85- 712 .

defensa social el Estado asume como suyo el conflicto en pro del interés colectivo, mientras que la Criminología coloca su énfasis en el delincuente, a quien cataloga como un enfermo social que requiere atención y tratamiento.

El garantismo penal viene a romper este paradigma en donde se enfatiza al delincuente y se privilegia el populismo punitivo, pretendiendo un Sistema penal fundamentado en la base de los derechos humanos y la consideración del derecho penal como ultima ratio.

El sistema Penal acusatorio generado a partir de la reforma constitucional de 2008 responde al modelo garantista propio de un Estado de Derecho que tiene pretende el derecho penal mínimo que se traduce en la reducción de la violencia tanto delictiva como la derivada de la reacción jurídico-penal, lo que contrario a las opiniones no supone mantener la exclusión de la víctima, por el contrario, al incluye como parte esencial del procedimiento penal y la solución del delito.

La irrupción de la victimología, el garantismo penal y la maximización de los derechos humanos son trascendentales en el redescubrimiento de la importancia de la víctima dentro del drama penal.

El nuevo rol de la víctima en el procedimiento penal acusatorio se proyecta a través de todo el ordenamiento jurídico, desde la fundamental Carta Magna hasta la Ley General de Víctimas, desde luego incluyendo el Código Nacional de Procedimientos Penales y la Ley Nacional de Mecanismos Alternativos de Solución de Controversias en Materia Penal (justicia restaurativa).

La justicia restaurativa no es una figura que favorece la impunidad, sino que es un modelo basado en la víctima, con la pretensión de que obtenga la reparación integral y contribuya en la solución del problema del delito.

El espectro de derechos para la víctima considerados en el apartado C) del artículo 20 constitucional se ve maximizado por la reforma del 2011, con lo que no solamente se consideran los derechos fundamentales en el sistema jurídico nacional sino también en los tratados internacionales, además todo este impulso ha derivado en la creación de la Ley General de Víctimas.

Con las reformas constitucionales del 2008 y 2011, se han dado los elementos necesarios para el redescubrimiento de la víctima en el procedimiento penal como sujeto procesal, pero además de proyectar la imprescindible incorporación de la desvictimación en la política criminológica de un Estado de Derecho para habilitar las estrategias idóneas para la atención de la víctima y aquellas que nos lleven a la prevención de la victimación. 
Para citar este artículo: Santacruz Fernández, Roberto y David Santacruz Morales, "El nuevo rol de la víctima en el sistema penal acusatorio en México", https://doi.org/10.22235/rd.v0i17.1572 Revista de Derecho, No 17 (jul. 2018), ISSN 1510-3714, ISSN On line 2393-6193: 85-112.

\section{BIBLIOGRAFÍA}

Alonso Rimo, Alberto, "La víctima en el Sistema de Justicia Penal I", art. cit. en Baca Enrique, Enrique Echeborúa y Josep Tamarit (Coords.), Manual de Victimología, España: Tirant lo Blanch, 2006.

Análisis situacional de las víctimas del delito 2016 http://informe.cndh.org.mx/menu. aspx?id=87 (Fecha de Consulta: 25 de julio de 2017).

Baca Enrique, Enrique Echeborúa y Josep Tamarit (Coords.), Manual de Victimología, España: Tirant lo Blanch, 2006.

Código Nacional de Procedimientos Penales

Constitución Política de los Estados Unidos Mexicanos

Dandurand, Yvon, Manual sobre Programas de Justicia Restaurativa, Estados Unidos: Naciones Unidas, 2016.

Fattah, Ezzat A., "Victimología: pasado, presente y futuro", Revista electrónica de Ciencia Penal y Criminología. Reflexiones RECPC 16-r2 (2014) http://criminet.ugr.es/recpc/16/recpc16-r2.pdf (Fecha de consulta: 23 de junio de 2017).

Ferrajoli, Luigi, Derecho Penal Minimo, http://www.nparangaricutiro.gob.mx/ Libros/31.-\%20E1\%20Derecho\%20Penal\%20M\%C3\%ADnimo\%20\%20 Ferrajoli,\%20Luigi.pdf (Fecha de consulta, 25 de junio de 2017).

Ferrajoli, Luigi, Garantismo Penal (trad. Marina Gascón), México: UNAM, 2006.

García-Pablos de Molina, Antonio, Tratado de Criminología 5a ed, España, Tirant lo Blanch, 2013.

Gómez Jaramillo, Alejandro, Un mundo sin cárceles es posible, México, Coyoacán, 2008.

Hernández Martínez, Ricardo, Elementos de Criminología, México: S/E, 2017, p. 45.

Ley General de Víctimas

Ley Nacional de Mecanismos Alternativos de Solución de Controversias en Materia Penal Lima Malvido, Ma de la Luz, “¿Qué aporta el conocimiento victimológico, a la sociedad? ¿y la sociedad al conocimiento victimológico?”, en Revista EGUZKILORE 
Roberto Santacruz Fernández - David Santacruz Morales, El nuevo rol de la víctima en el sistema penal acusatorio en México, 85- 712 .

Número 26 (2012), 87-106. http://www.ehu.eus/documents/1736829/2177136/ Lima+Eguzkilore+26-12.pdf, p. 90 (fecha de consulta: 25 de junio de 2017).

Luna Castro, José Nieves: "Introducción y características del Nuevos sistema de justicia penal”, art. cit. en http://www.ijf.cjf.gob.mx/examenaptitud/2015/seleciondepersonal/ Luna\%20Castro\%20J\%C3\%B3se\%20Nieves\%20Fundamentos\%20del\%20 nuevo\%20sistema\%20de\%20justicia\%20penal.pdf (fecha de consulta 25 de junio de 2017).

Malo Camacho, Gustavo, Derecho Penal Mexicano 3a reimp., México: Porrúa, 2016.

Marchiori, Hilda, Criminología. La Víctima del delito, 10a ed., México: Porrúa, 2017.

Márquez Cárdenas A E, 2La victimología como estudio. Redescubrimiento de la víctima para el proceso penal. Prolegómenos. Derechos y Valores” 2011XIV27-42. Disponible en: http://www.redalyc.org/articulo.oa?id=87619038003. (Fecha de consulta: 15 de junio de 2017).

Medellín Urquilaga, Ximena, Principio pro persona, México: CDHDF, 2013.

Muñoz Conde, Francisco y Hassemer, Winfried, Introducción a la Criminología y Derecho Penal, España, Tirant lo Blanch, 1989.

Neuman, Elias, "Benjamín Mendelshon: precursor de la autonomía científica de la Victimología”, en Iter Criminis, Revista de Ciencias Penales, INACIPE $3^{\circ}$ época, número 7 (2006).

Programa Nacional de Atención a la Víctima 2014-2018, del Sistema Nacional de Atención a la Víctima https://www.gob.mx/cms/uploads/attachment/file/153590/PAIVaprobado-por-el-SNAV-20-mayo-20151.pdf (fecha de consulta: 20 de julio 2017)

Sampedro-Arrubla, Julio Andrés, "La justicia restaurativa: una nueva vía, desde las víctimas, en la solución al conflicto penal", en International Law, Revista Colombiana de Derecho Internacional, 87-124 (2010). http://www.scielo.org.co/pdf/ilrdi/n17/ n17a04.pdf (Fecha de consulta: 25 de junio de 2017).

Tamarit, Josep Ma, "La victimología: cuestiones conceptuales y metodológicas" art. cit. en Manual de Victimología (Baca Enrique, Echeborúa, Enrique y Tamarit, Josep, Ma. Coordinadores), España: Tirant lo Blanch, 2006.

Villabella Armengol, Carlos Manuel, La Investigación y la comunicación cientifica en la ciencia jurídica. México, BUAP-ICI-Universidad de Camagüey, 2009.

Zamora Grant, José, La víctima en el nuevo sistema acusatorio, UNAM-IFP, México, 2014.

Zamora Grant, José, Derecho Victimal. La víctima en el nuevo sistema penal mexicano, $3^{a}$ ed, México, INACIPE, 2016. 